\title{
LA CIUDAD DE DENIA Y LA PRODUCCIÓN DE CERÁMICAS VIDRIADAS CON DECORACION ESTAMPILLADA. EL ALFAR DE LA CALLE TEULADA
}

Por

JOSEP A. GISBERT

Este informe tiene por objeto la presentación de una variedad cerámica, de cronologia islámica, ligada a la ciudad de Denia. La evidencia arqueológica atestigua el papel del núcleo urbano como centro de producción alfarera, además del uso y presencia de estas cerámicas en los ajuares de época árabe.

Esta variedad, que denominamos recientemente "cerámica vidriada con decoración estampillada" (1), tiene una gran homogeneidad técnica y tipológica. En todos los casos, está recubierta de vedrio que cubre el interior y borde externo de las piezas y presenta una decoración estampillada, aplicada sobre el barro verde mediante punzones individuales que se repiten en una o varias franjas circulares y concéntricas. Las estampillas aportan un interesante repertorio decorativo, con motivos geométricos, vegetales $y$, quizás, simbólicos.

E) estudio de estos productos: características técnicas y formales, comercialización y ámbito de circulación de la cerámica, constituye una compleja problemática y será el fruto de un trabajo más amplio y en que el estado de la investigación permita la interpretación de datos más representativos. El artículo que nos ocupa tan sólo pretende documentar el yacimiento arqueológico - alfar - que confirma la producción in situ de estas cerámicas, los materiales conocidos, el estado actual del mismo y los trabajos provectados por el Museo Arqueológico de Denia para su progresivo estudio y protección.

En última instancia, el objetivo primordial es valorar e insertar el caso de Denia como manifestación puntual de un fenómeno generalizado de producción alfarera y exportación de cerámicas de lujo, confirmado por la arqueología en diversos núcleos urbanos de al-Andalus y con un desarrollo, en el caso de esta variedad, al parecer, sincrónico.

(1) GISBERT, Josep A, "La cerámica vidriada con decoración estampillada en la Denia islámica", comunicación a las III Jornadas de Cultura Arabe e Islámica, Madrid, 1983 (en prensa). 
Denia es una ciudad costera, situada al noroeste de la provincia de Alicante. Pertenece a la comarca de El Marquesat, también conocida como Marina Alta. Su término presenta una variada topografía, característica de la franja litoral del Mediterráneo peninsular.

El Castell o fortaleza de Denia está situado sobre una elevación montañosa, aislada en la llanura litoral y junto al mar, hecho que caracteriza un privilegiado punto geográfico. Su altura máxima es de 66 metros sobre el nivel del mar. Tiene suaves pendientes, excepto en la cara norte, que actualmente es un pronunciado precipicio a causa de la abusiva extracción de piedra caliza en época reciente.

La ciudad se sitúa, predominantemente, al este y sur de la elevación, con una clara expansión urbana hacia el oeste. Los restos del núcleo urbano de época islámica, ciudad $y$ distintos arrabales, se hallan casi totalmente cubiertos por la actual trama urbana. Este emplazamiento determina la existencia de una compleja arqueología urbana, actualmente en vías de revisión y estructuración. con el fin de lograr la máxima eficacia en la documentación, protección y conservación del patrimonio arqueológico (lámina II)

El marco físico favorece la expansión urbana de la Denia islámica, que goza. además, de una fuerte implantación humana desde la antigüedad. La importancia de estos factores viene confirmada por las escasas fuentes árabes referentes a Denia, que resaltan su situación estratégica y la existencia de un buen puerto que activa el comercio marítimo (2).

\section{El alfar de las calles Verger y Teulada}

\section{LOCALIZACIÓN Y SITUACIÓN}

La reciente expansión urbana hacia el oeste de la ciudad de Denia ha determinado la detección, en una amplia área que abarca las calles Verger y Teulada, de los restos de un yacimiento arqueológico de época islámica. Los materiales documentan una escombrera de alfar: útiles con una funcionalidad específica, así como defectos de cocción que prueban la producción de ciertas variedades de cerámica árabe.

El lugar en donde se sitúa el yacimiento se denomina "Camp Roig", topónimo que hace referencia al color de las tierras. La geología confirma esta denominación (3), en tanto que se trata de un suelo de arcillas rojas limosas, acumuladas junto con cantos en costras discontinuas. Esta composición es la propia de las canteras de extracción de arcillas (láminas I y ili).

Otro dato de interés es la existencia de recursos para el abastecimiento de agua en sus alrededores. Hay afloramientos acuíferos a escasa profundidad. Carece de fuentes y el agua se extraía tradicionalmente por medio de norias. Además, el Camp Roig es atravesado por la acequia de Santa Paula, con un trazado de probable origen islámico y quizás destinada a la irrigación y abastecimiento del alfar (4).

(3) Mapa Geologico y Minero de España, núm. 796 (30-31), Gandía, Ministerio de Industria, Madrid, 1975.

(4) TORRES BALBAS, L., Ciudades hispano-musulmanas, tomo l, s. f., p. 138. 
Por tanto, el marco físico es propicio para el emplazamiento de un alfar, a। contar con materia prima y abundante agua.

La ubicación del alfar, en relación con la topografía urbana de la ciudad árabe de Denia, es bien explícita. El área del yacimiento se encuentra al exterior y en los alrededores del núcleo urbano islámico y está situado entre dos ejes fósiles: uno de carácter geográfico, al sur, el barranc de Santa Paula; al norte, el camino de acceso más importante al recinto urbano: el camí vell d'Ondara. No obstante, hallazgos $\vee$ noticias antiguas sitúan una zona de cementerio o necrópolis árabe entre el alfar y la mencionada vía de comunicación.

Todos estos caracteres, la situación extramuros, la delimitación por ejes geográficos y el marco físico, tienen paralelos con otras ciudades de al-Andalus (5) Ilámina II).

\section{HISTORIA DE LOS HALLAZGOS}

En los archivos del museo hay noticias de la destrucción, en 1977, de un horno en uno de los solares del área (6), cuya descripción coincide con la escasa bibliografía existente sobre el tema (7). De este hallazgo se conservan pocos materiales, entre los que destacan los elementos de alfar.

La realización de pozos de cimentación en otro solar contiguo (8) documentó una gran bolsada de material arqueológico. Los hallazgos, que se conservan en los fondos del Museo Arqueológico de Denia, ilustran la producción de, al menos, las.variedades cerámicas de alcafoll y cerámica con vedrio verde y decoración estampillada, y algunos tipos de cerámica común: candil de piquera, arcaduces, etc. Estos materiales, generalmente de cocción defectuosa, estaban entremezclados con algunos elementos propios de un alfar: rollos, atifles, etc.

En febrero de 1983, el Museo Arqueológico programó una prospección superficial en una parcela situada en la partida de Madrigueres Sur (finca de San Carlos) (9). Los materiales predominantes son los típicos fragmentos de elementos de alfar. Ello amplia el radio del yacimiento, que parece ocupar una superficie considerable.

\section{LOS MATERIALES}

\section{A) CERÁMICA VIDRIADA ESTAMPILLADA}

Las piezas que presentamos aparecieron en un denso relleno de arcillas rojas, asociadas a piezas decoradas con la técnica de alcafoll.

\footnotetext{
- (5) Idem. nota 4, p. 131.

(6) Solar número 1 de la manzana 53 del plano del Ministerio de Hacienda, a escala 1/1.000, del casco urbano de Denia.

(7) GONZALEZ MARTI, M., Cerámica del Levante español, siglos medievales, tomo I, Barcelona, 1944. pp. 2729. MARTINEZ ORTIZ, J. y SCALS, J. de, Colección cerámica del Museo Histdrico Municipal de Valencia Paterna-Manises, Valencia, 1967 , pp. 40-41.

(8) Solar contiguo al de la nota 6 , en la avenida del Montgó

(9) Parcela 25 a, del poligono 30 del parcelario rural del Instituto Geográfico y Catastral
} 
Tienen una marcada homogeneidad técnica. Las pastas son de color rojo ladrillo, de textura compacta y con puntitos de desgrasante de color rojo de tono fuerte u ocre amarillento. El exterior de las piezas va recubierto con un engobe de tono ocre amarillento y el interior está decorado con un vedrio de color verde claro y blanquinoso, sensiblemente alterado por una cocción defectuosa (en realidad, es de color verde oscuro y oliváceo).

En cuanto a la tipologia, se adscriben a la forma de Ataifor (10), posiblemente carenado, como lo prueban algunos hallazgos de esta variedad. El diámetro de las bases oscila entre los 9 y 11 centímetros. Los fragmentos decorados con la técnica de alcafoll, con trazos de manganeso sobre fondo melado, también se adscriben a la forma de ataifor carenado. No obstante, los hallazgos atestiguan el uso de esta técnica en jofainas (11), de menores dimensiones.

Las estampillas presentan una disposición radial entre dos acanaladuras situadas en el fondo interno, si bien la distancia entre impresiones y de éstas respecto a las acanaladuras carece de regularidad. Cada pieza tiene sucesivas improntas realizadas con punzones individuales. Los motivos decorativos son rosetas, de cinco a ocho pétalos, inscritas en cartelas circulares o quebradas.

\section{Número 1: Lámina IV a}

Diámetro de la base: 11 centímetros.

Estampillas: rosetas de cinco pétalos con puntos entre ellos. Cartela circular, de 1,3 centímetros de diámetro. Presenta un total de 11 improntas con disposición radia! poco regular.

Número 2: Lámina IV, b

Diámetro de la base: 10,3 centímetros

Estampillas: rosetas de ocho pétalos rómbicos en cartela aparentemente quebrada y disposición radial regular.

\section{Número 2: Lámina V}

Diámetro de la base: 9 centímetros.

Estampillas: roseta de ocho pétalos con interpunciones esporádicas. Cartela circular de 1,5 centímetros de diámetro. Disposición radial regular y una estampilla en el centro de la pieza.

La homogeneidad de punzones de los tres fragmentos del alfar contrastan con los datos conocidos de la ciudad (12), en donde destacan la diversidad de motivos decorativos de los punzones, que presentan desde temas geométricos (cruciformes, cículos concéntricos, red con interpunciones de relleno), hasta palmetas o fiores del repertorio vegetal. Como ejemplo de la diversidad de punzones de estas piezas, presentamos algunas procedentes de la ciudad y alcazaba del Castell de Denia (lámina VIII).

B) ELEMENTOS DE ALFAR

Las bolsadas de materiales arqueológicos procedentes del área del alfar,

(10) hOSSELLO BORdOY, G., Ensayo de sistematización de la cerámica árabe en Mallorca, Palma de Mallorca, 1978 , pp. 16-19.

(11) idem. nota 10, pp. 56-57.

(12) Idem. nota 1. 
fundamentalmente, estaban constituidas por la aglomeración de estos elementos.

Los rollos, denominados en los alfares de Paterna "morrells" o "llongots" (13), son tubos macizos de cerámica, de sección cilíndrica y levemente curvados, con un extremo puntiagudo. Tiene unos 40 centímetros de lago y 8 de grosor, y presenta dos variantes en las puntas: una lisa con apéndice y otra decorada con digitaciones (lámina VI).

Respecto a su funcionalidad, el hecho de presentar parte de ellas manchas de vedrio y fragmentos de bordes de vaso pegados confirman su utilización para la separación de apilamientos verticales de piezas dentro de la cámara del horno. Por otra parte, su uso como materiales (de construcción) para la construcción de la bóveda o "garbell» que separa la caldera de la cámara de cocción superior del horno queda confirmado por la bibliografía $(14)$ y coincide con las noticias que tenemos sobre la destrucción de un horno en el área del alfar.

Los atifles o trébedes presentan una tipología característica, en forma de estrella de tres puntas, con apéndices en el extremo de cada una de ellas. Tienen un diámetro aproximado de 9 a 11 centímetros, y su función, de acuerdo con la bibliografía, era la de separar las piezas entre si dentro de la cámara de cocción (lámina $\mathrm{V}$ ).

El tercer elemento de alfar es el menos representado. Tiene forma de "S" $y$ una longitud máxima de 12,5 centímetros. No se conoce su funcionalidad, si bien en los alfares de Paterna, ya en época cristiana, parecía utilizarse para sacar del horno pruebas de cocción y vitrificación, en conexión con una cadena: también de arcilla (lámina VI).

Todos estos útiles se hallan documentados en la escombrera del alfar de Casa Destrull de Mallorca (15), de época árabe, así como parte de ellos en el alfar de Toledo (16).

\section{CRONOLOGÍA}

La datación de las piezas de cerámica vidriada con decoración estampillada quizás sea uno de los aspectos más problemáticos de las mismas, debido a que la bibliografía existente sobre estas producciones es limitadísima y, en todos los casos, los materiales publicados carecen de un contexto arqueológico que permita delimitar su cronología.

Las piezas de Mesas de Villaverde (Bobastro), publicadas por Cayetano de Mergelina (17) y, posteriormente, por Juan Zozaya (18), son de tipología simi-

(13) Idem, nota 7 .

(14) ldem. nota 7.

(15) Idem. nota 10, pp. 127-130.

(16) AGUADO VILLALBA, J., "Cerámica hispano-musulmana de Toledo", comunicación al / Coloquio Imternacional de Cerámicas Medievales del Mediterráneo Occidental, Toledo, 1981 (en prensa).

(17) MERGELINA, C de, "Bobastro. Memoria de las excavaciones realizadas en las mesas de Villaverde. El Chorro (Málaga)a, Junta Superior de Excavaciones y Antigüedades, núm. 89, Madrid, 1927.

118) ZOZAYA, J., "Aperçu general sur la céramique espagnolen, La Céramique Médievale en Mediterranée Occidentale, X-XV siècles, Valbone, 1978; “Cerámica andalusí, Cerámica esma/tada española, Barcelona, 1981, pp. $37-50$. 
lar a las descritas (ataifor tipo II de Rosselló) y presenta estampillas con palmetas. J. Zozaya propone unas fechas muv altas para la misma: época emiral-califal (711-1035 d. C.).

Remedios Amores estudia un conjunto de cerámicas similares procedentes de Lorca (Murcia) y les adscribe una cronología almohade (19)

J. Aguado (20) documenta la existencia de una escombrera de alfar en el núcleo urbano de Toledo, con una producción de diversas variantes: cuerda seca, verde y morado, alcafoll, etcétera, junto con cerámicas estampilladas de típología y punzones similares a la que nos ocupa. Propone como datación el siglo XI.

Existen algunas referencias a hallazgos de estas producciones en el País Valenciano. Tal es el caso de las piezas del Museo de Villena (21), recubiertas de vedrio verde $y$ melado y con punzones con motivos cruciformes o, más recientemente, los hallazgos que publica A. Bazzana, procedentes de Santa $\mathrm{Fe}$ (Oliva), a los que apunta una cronología del siglo XI (22).

En relación con la bibliografía existente sobre el tema y la evidencia arqueológica, podemos señalar algunas hipótesis. Tal es la posibilidad de producción de cerámica con vedrio monocromo y decoración estampillada durante la época taifa (siglo XI), que coincidiría con el cenit de. la expansión de la ciudad árabe de Denia. La poca diversidad de punzones del alfar y la presencia de cerámicas decoradas con la técnica de alcafoll en su contexto parecen apoyar la cronología taifa del alfar de Denia. No obstante, esta producción continuará en actividad durante la época almorávide-almohade, con una notable diversificación y enriquecimiento de los motivos de las estampillas y la utilización de las mismas en el repertorio decorativo de cerámicas comunes con decoración en relieve (tinajas y alcadafes).

Otro aspecto interesante es el de la difusión y comercialización de estas cerámicas. El estado de la investigación no permite valorar la incidencia de estos productos. Sin embargo, lo cierto es que diversas noticias apuntan su presencia en la ciudad de Xàtiva y en puntos del poblamiento rural de las comarcas de la Safor, Marina Alta y la Costera.

\section{CONCLUSIÓN}

En definitiva, se ha procedido a la individualización de un alfar de cronología islámica, con una producción de cerámica vidriada con decoración estampillada, lo que conlleva la publicación de un yacimiento inédito, su inclusión en la topografía de la ciudad árabe de Denia y su valoración como centro industrial de cerámicas de lujo, sin paralelos en el País Valenciano y asociado, como el

(19) AMORES LLORET, Remedios, "Cerámica con decoración estampillada de Lorca (Murcia)w, // Co/oquio /nternacional de cerámicas medievales del Mediterráneo Occidental, Toledo, 1981 (en prensa).

(20) idem, nota 16 .

(21) SOLER GaRClA, J. M., "Castillo de Salvatierra", Rev. Castillos de España, 80, Madrid, 1975, pp. 34-48.

(22) BAZZANA, A., "Céramiques médiévales. Les méthades de la descriptian analytique appliquées aux productions de l'Espagne Orientalew, Mellanges de la Casa de Velazquez, tomo XVI, París, 1980, pp. 57-95, ver página 80 y fig. 10; «El yacimiento medieval de Santa Fe de Oliva (Valencia). Estudio de su cerámica», Noticiario Arqueológico Hispánico, 18, Madrid, 1984, pp. 255-339. 
caso de Toledo o Mallorca, al funcionamiento de un gran centro urbano de época islámica.

Esta variedad de cerámica presenta una compleja problemática en cuanto a sus antecedentes, fenómenos de difusión y comercialización, funcionalidad y cronología, $y$ el desarrollo de las investigaciones, sin duda, valorarán estas piezas.

El Museo Arqueológico de Denia, en vista del interés del yacimiento arqueológico, ha solicitado al M. I. Ayuntamiento su inclusión en el Plan Especial del Patrimonio Histórico Artístico (23) y tiene prevista una serie de prospecciones sistemáticas para la delimitación del área y posterior estudio (lámina II).

123) Plan Especial del Patrimonio Históxico Artístico y modificación puntual del Plan General de Denia. Equipo redactor: R. Benito Roces, S. Varela Botella, E. A. Llobregat Conesa y M. Baena del Pino Aprobado por el M. I. Ayuntamiento de Denia, por acuerdo pleno, el día 21 de agosto de 1981 


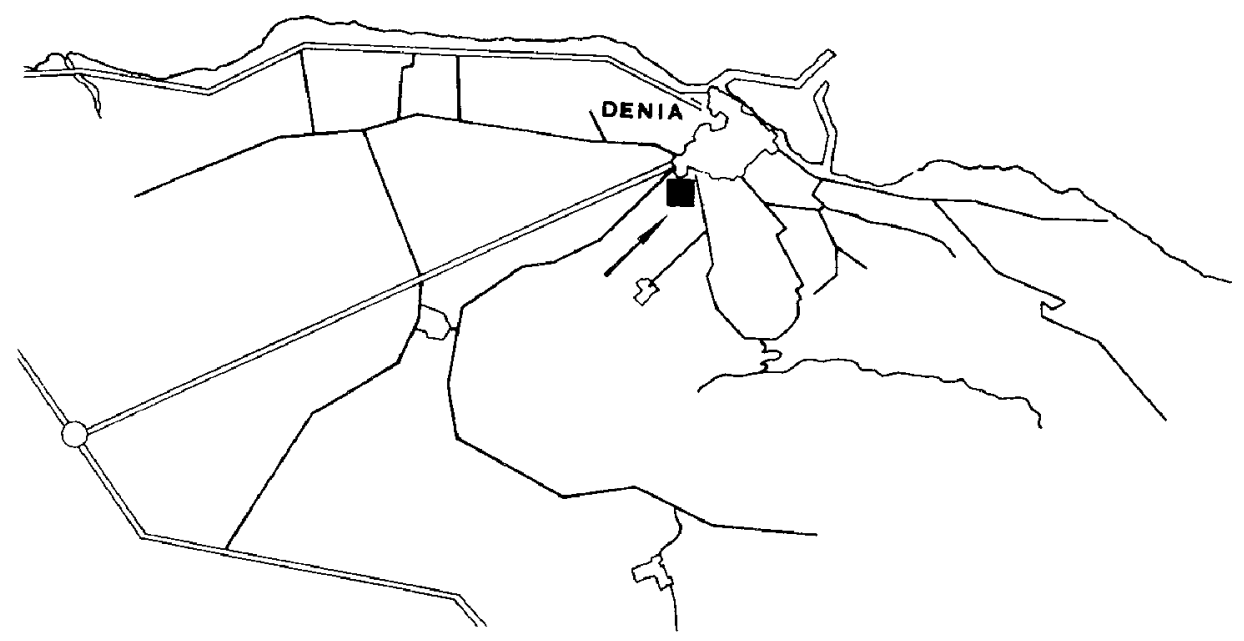

1.-Denia. Situación de los Alfares. 


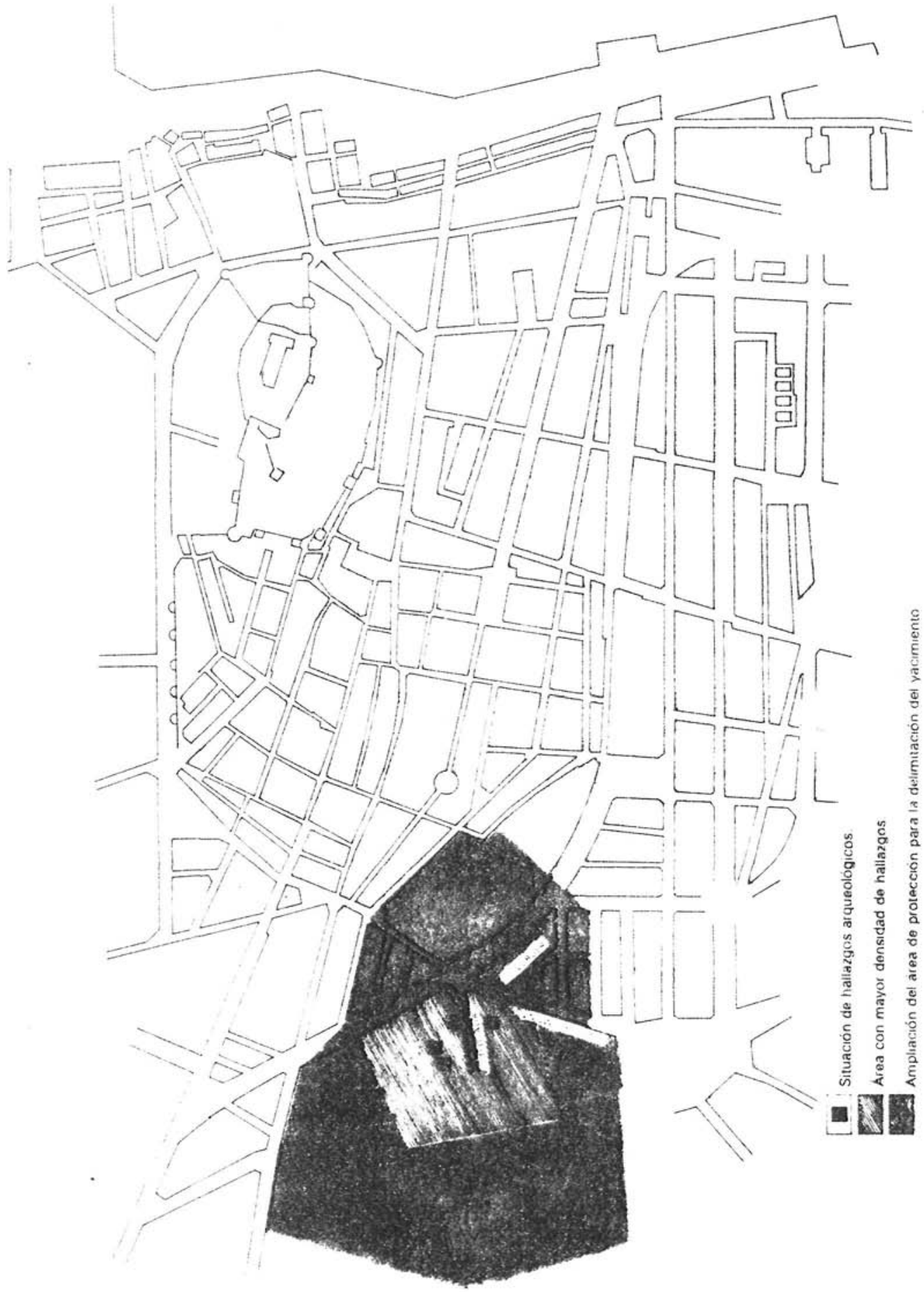

II. - Casco urbano de Denia Localización de los alfares y señatización de áreas de protección propuestas 


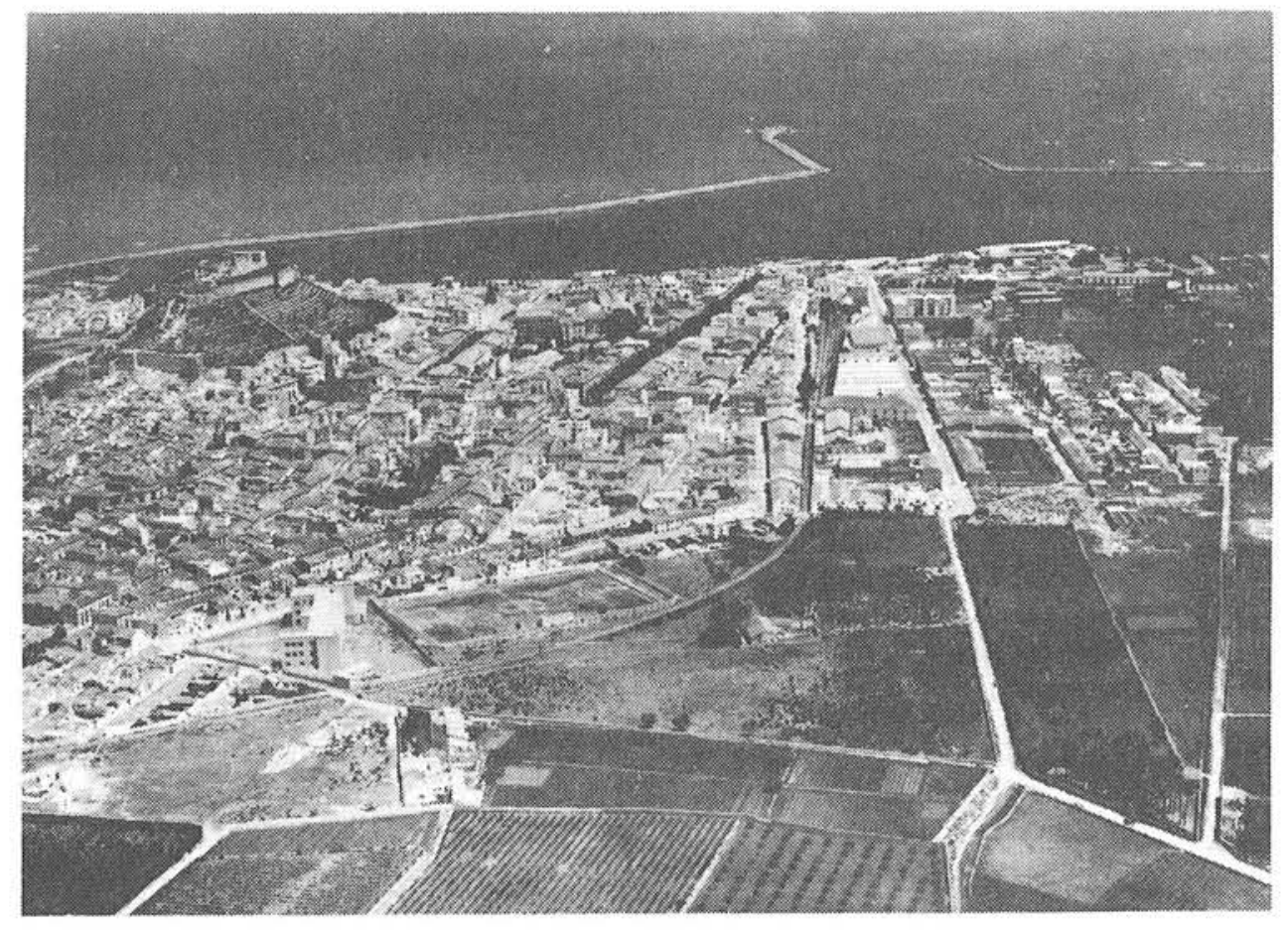

III.-El Camp Roig en los años 60, antes de la expansión urbana hacia el oeste. 
DENIA Y LA PRODUCCIÓN DE CERÁMICAS VIDRIADAS... i Gisbert
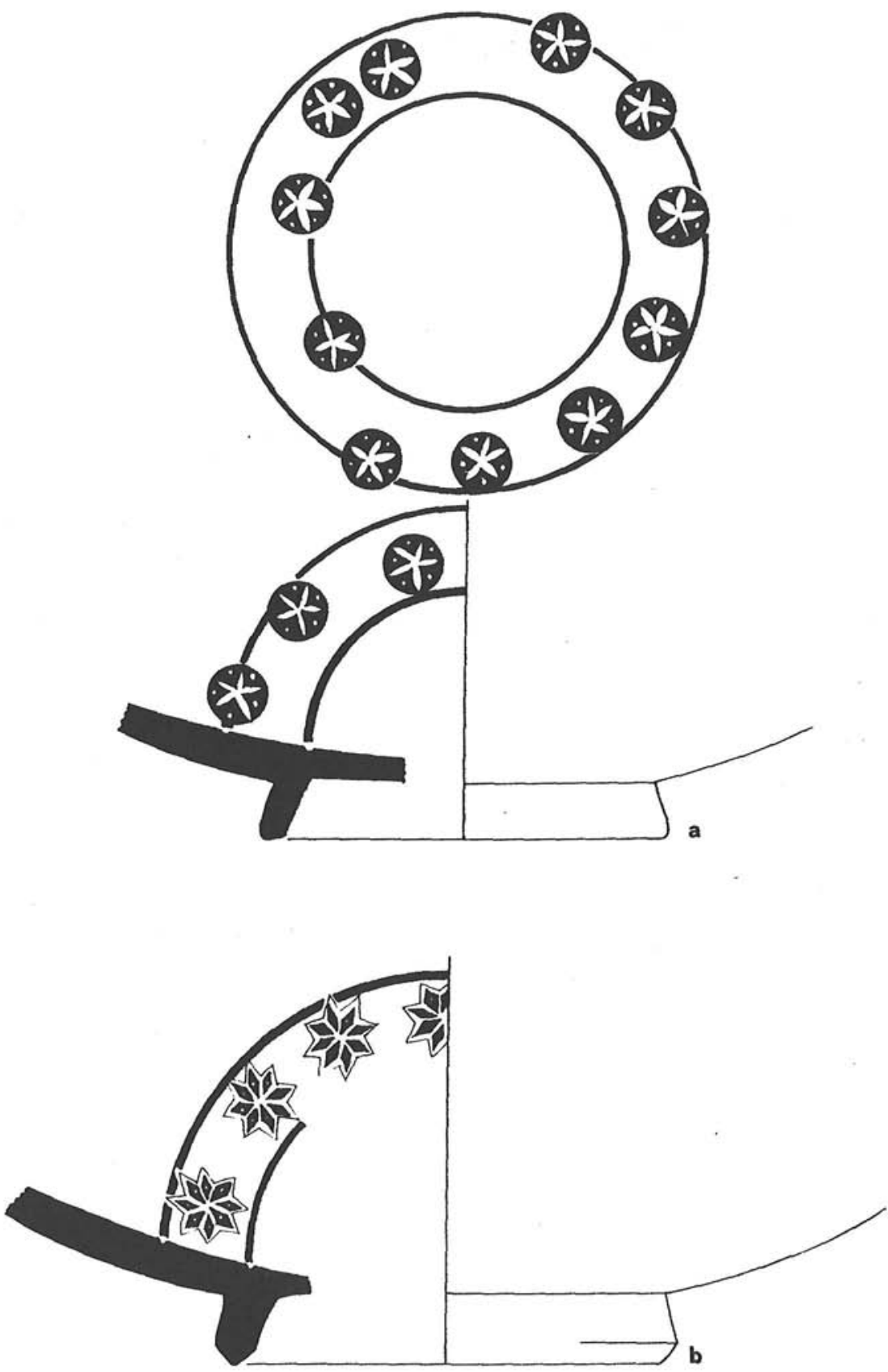

IV. - Cerámica con decoración estampillada, defectuosa de cocción, procedente del Alfar 


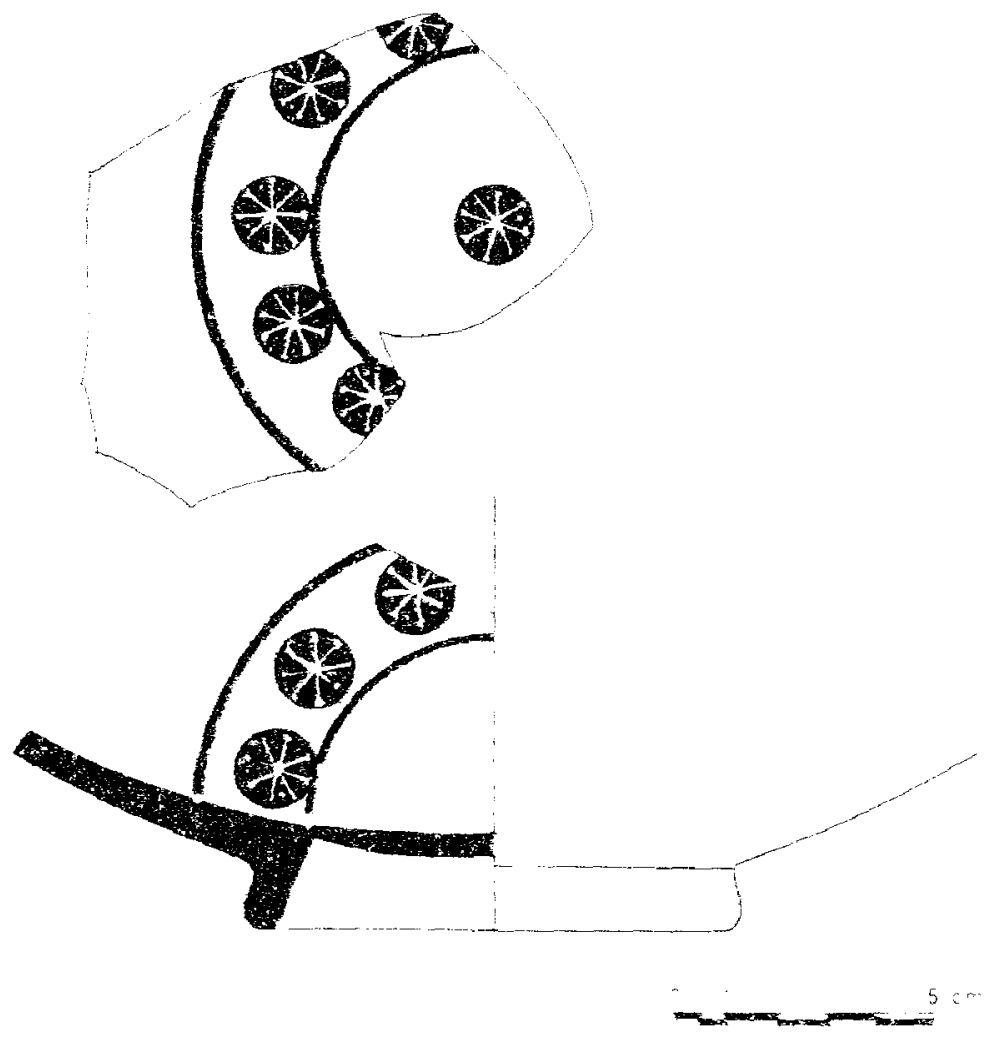

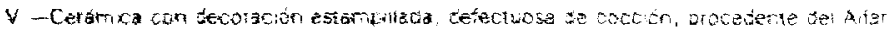


DENIA Y LA PRODUCCIÓN DE CERÁMICAS VIDRIADAS ... I Gisbert

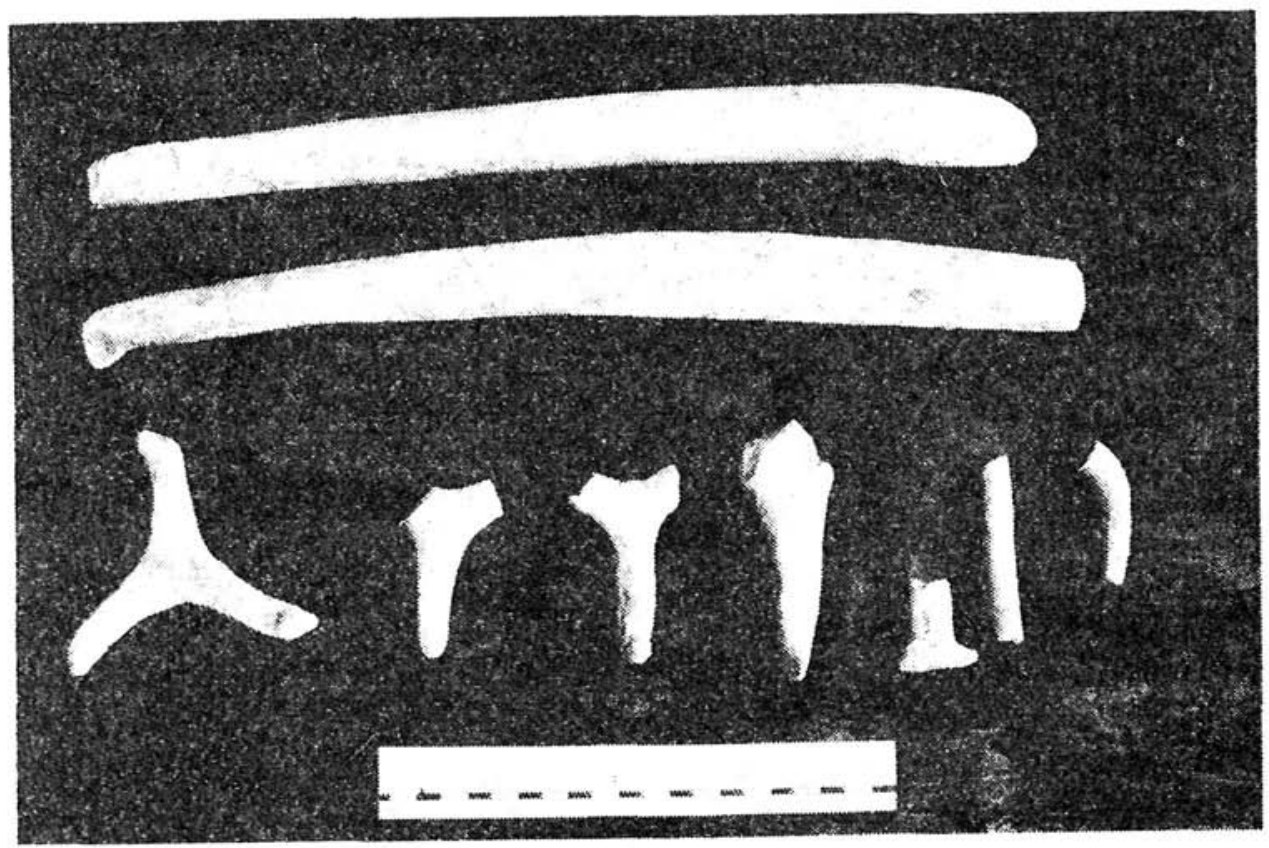

VI - E'ementos de Altar, de uso nabitua: en ta procuccion ceramica Riolios y atifes 

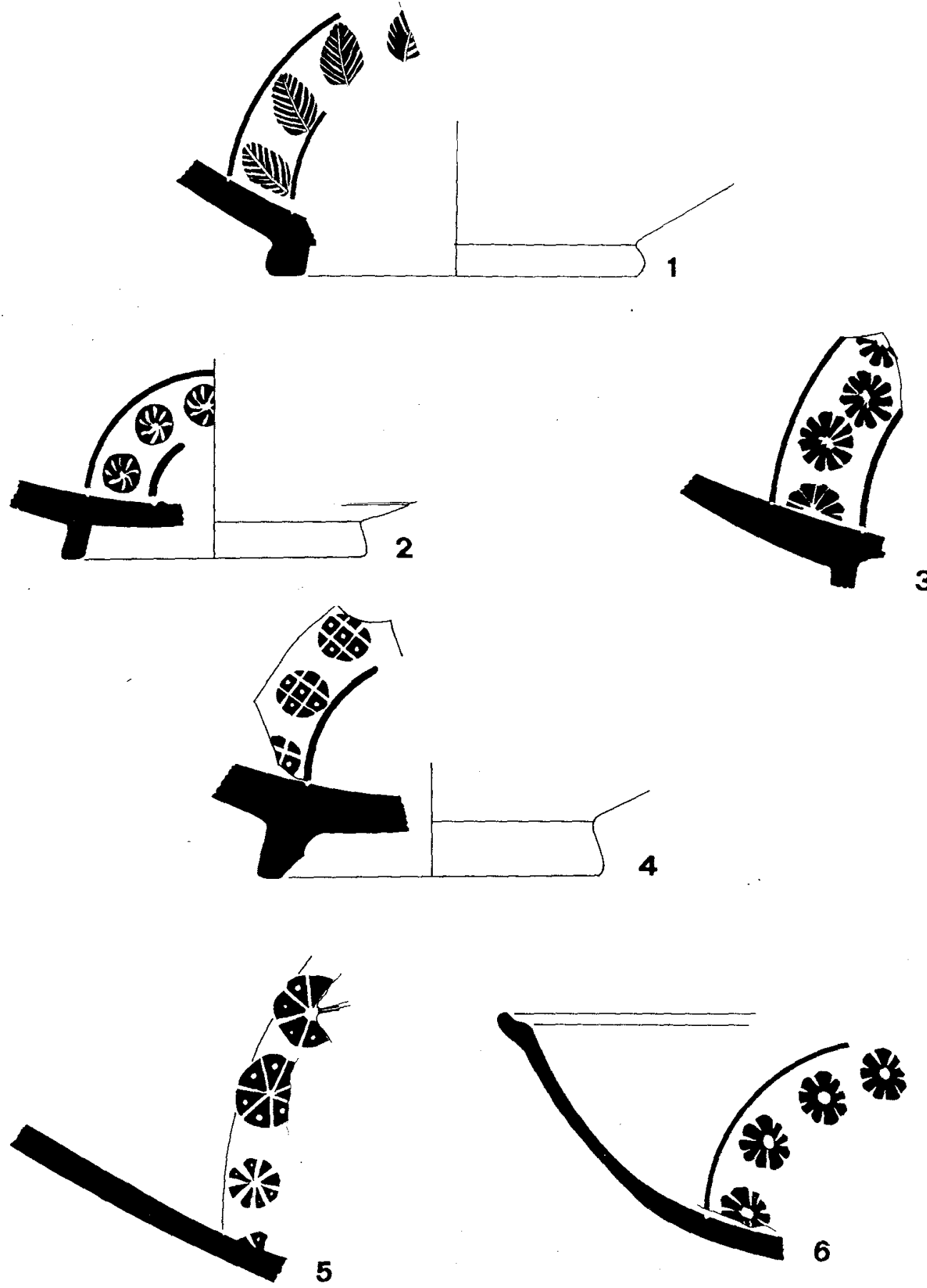

VII. - Ejemplos de esta producción cerámica, hallada en diversos puntos del núcleo urbano de Denıa 